\title{
NEW AND IMPROVED DEVICES FOR FISH CULTURISTS
}

From BULLETIN OF THE BUREAU OF FISHERIES, Volume XXVII, 1908

Proceedings of the Fourth International Fishery Congress : Washington, 1908
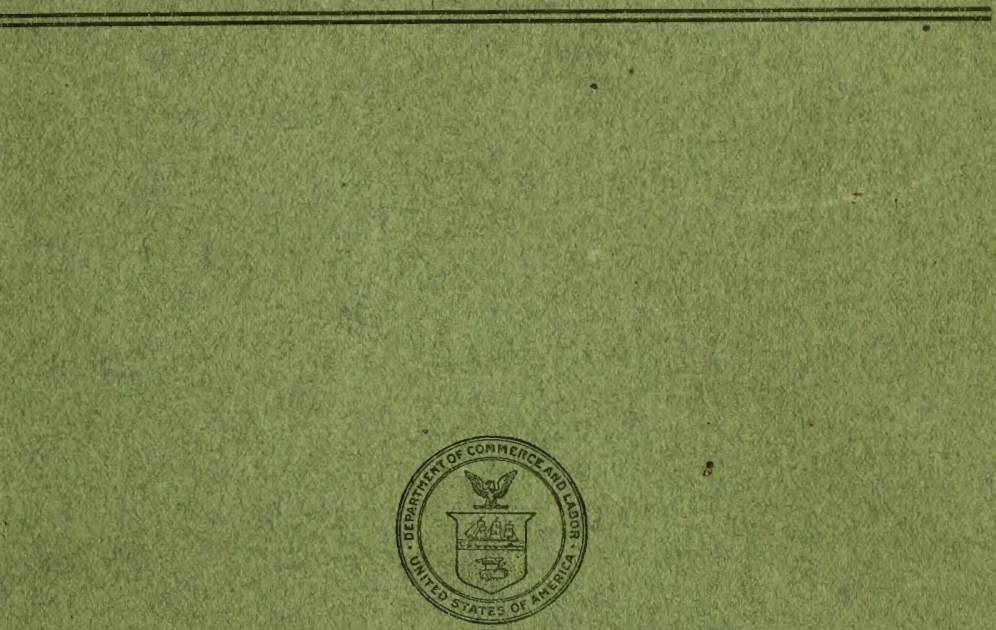

WASHINGTON : : : : : : GOVERNMIENT PRINTING OFFICE : : : : : : 1910 


$$
\text { ช }
$$





\section{NEW AND IMPROVED DEVICES FOR FISH CULTURISTS}

From BULLETIN OF THE BUREAU OF FISHERIES, Volume XXVIII, IgO8

Proceedings of the Fourth International Fishery Congress " : Washington, I9o8

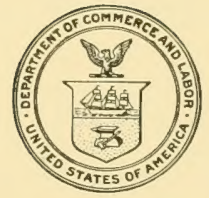

WASHINGTON : : : : : : GOVERNMENT PRINTING OFFICE $: \quad: \quad: \quad: \quad: \quad 1910$ 


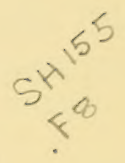

BUREAU OF FISHERIES DOCUMENT NO. 700

Issued April, 1910

$$
\begin{aligned}
& \text { A. } 301910 \\
& \text { Oof be }
\end{aligned}
$$




\title{
NEW AND IMPROVED DEVICES FOR FISH CULTURISTS \\ $+$
}

\author{
By Alfred E. Fuller \\ U. S. Fisheries Station, Northville, Mich.
}

Models presented before the Fourth International Fishery Congress

held at Washington, U. S. A., September 22 to 26, 1908 
CONTENTS.

s

1. Artificial bass nest _............

2. Bass fry retaining screen and trap _ _

3. Collecting tub_

4. Fish retainer

5. Fish attendant's outfit

6. Seine for collecting fingerling bass

7. Shipping case for fish eggs

992 


\title{
NEW AND IMPROVED DEVICES FOR FISH CULTURISTS.
}

\author{
$\$$ \\ By ALFRED E. FULLER, \\ U.S. Fisheries Station, Northville, Mich.
}

$*$

ARTIFICIAL BASS NEST.

[Exhibit I. Fig. 1, pl. crv.]

This form of bass nest, like others in use, consists primarily of a container for the gravel, constituting the nest proper, and a shield to furnish the seclusion required by the nesting fish. Both container and shield, however, are of distinctive design, and the shield, which is detachable, is provided with a waterproof record holder and indicator projecting above the water.

The nest proper is an iron hoop 2 feet in diameter, made of $I / 2$-inch by $\pi / 8$-inch band iron. This hoop, placed in the pond and filled with gravel, holds the latter within its circumference without the necessity of any bottom and may be left in position permanently. Riveted at each of 3 quartering points on the outside of the hoop is an iron socket or slot, of size to accommodate a standard $\mathrm{I}$ inch wide and $\mathrm{I} / 8$ inch thick. By means of these slots the removable shield is adjusted to the hoop.

The shield, 2 feet high and semicircular to fit one side of the hoop, is made of ordinary galvanized sheet iron riveted to three iron standards. The standards, which are I inch wide by $1 / 8$ inch thick, extend 2 inches below the sheet of iron they support, and are pointed at the lower end for ready adjustment to the sockets in the hoop. The two end standards are 26 inches in height and flush with the top edge of the shield. The middle standard is higher, projecting above the shield to hold the indicator and record case. The height of the projection is determined by the depth of the water in which the nest is used, the indicator to be always visible above the surface of the pond. The shield and container are coated with paint.

The record holder consists of a waterproof case to contain cards or small sheets of paper and has a number and an indicator on its face. The case is made of 2 rectangular pieces of thin sheet metal, preferably copper, $21 / 2$ by 5 inches, with rolled edges to permit one side of the case to slide upon the other. Into the back are slipped the car ls or sheets of paper containing detailed 
records of the nest. The nest number is stamped or painted on the upper half of the face of the case; in the lower half is fixed a metal pointer, in a dial upon which appear symbols which will indicate to the fish culturist whether the nest is "cleaned up" or contains eggs or fry. A metal pocket is soldered upon the back of the case, by means of which to fit it to the tall standard of the shield.

The especial advantages of this nest are as follows:

I. The shield can be removed to permit placing the retaining screen around the nest without roiling the water or disturbing the nest proper, thereby avoiding injury to the fry by the rolling of the gravel.

2. The nest proper, remaining permanently in the pond, is always in readiness for use without the expenditure of labor to renew each year, and when once installed requires only attaching of the shield, which can be done in the space of a moment.

3. The nest, being of heavy metal, will remain stationary in the pond without being weighted down to prevent floating.

4. A separate and complete record of each nest can be kept as its product advances to different stages, while its condition can be determined from the shore at a glance without disturbing the fish by entering the water or going to the nest in a boat.

5. Nest and shield are easily stored. Fifty of the shields require a space but 2 feet wide, 2 feet high, and 26 inches long.

\section{BASS FRY RETAINING SCREEN AND TRAP.}

[Exhibit 2. Fig. 2, pl. crv.]

The retaining screen and trap exhibited is intended for use in connection with the bass nest just described. It combines with the ordinary cylindrical retainer a device by means of which the fry are entrapped and may be readily lifted from the nest. Certain improvements in the construction of the retainer are also important features.

The retaining screen is made of a piece of 14 -mesh galvanized wire cloth 3 feet in width, stretched around a frame consisting of two iron hoops and 4 iron standards. The hoops are made of $1 / 8$ by $\mathrm{I}$ inch iron bands and are 3 feet in diameter; the standards are 3 feet high. The joinings are everywhere made with stove bolts, which also secure the wire cloth to the frame. At the seam the wire cloth is lapped directly over one standard and an extra upright $3 \mathrm{I} / 2$ feet long is bolted over the lap. The circular inclosure thus built is readily "knockdown" for storage purposes. Upon the projecting upright is fitted the record holder, which was attached to the nest shield described in exhibit $\mathrm{I}$ and is now to be transferred to carry on the record for the fry. All metallic parts are painted.

The trap is within the retainer. It consists of a hoop fitted over the bottom hoop of the retainer and securing about its circumference a piece of bobbinet 
so shaped and seamed as to form a blunt cone about 2 feet high when held in place within the wire-cloth screen. The top of this cone is open, the bobbinet here fitted and secured to an iron ring 4 inches in diameter. To hold the cone in position, two cords attached on opposite sides of the opening are carried to the upper rim of the retainer and there fastened by means of bent-wire hooks at the ends of the cords.

As the bass fry ascend from the nest their natural tendency is to follow the inside of the cone upward to the 4 -inch opening, through which they pass to the upper section of the retaining screen. After they have all ascended, this opening is closed with a tight-fitting cap made of a circular piece of bobbinet held in at the edge by an elastic gathering string. The fish are then in captivity. To remove them from the pond, the apparatus is lifted to the surface of the water, the cords holding the cone are released, and the cone telescopes, forming a scaff net, which is then detached from the bottom hoop of the retainer, placed over the collecting tub, and the fish liberated therein.

The advantages of this combined retaining screen and trap are as follows:

I. All the fry that are able to rise from the nest can be captured.

2. They can be taken from the trap at any time desired without regard to roiliness of the water or low temperature.

3. The device is useful in the capture of bass fry in inland lakes which have become overstocked and from which it is desirable to transfer the fish to barren waters or waters more accessible to sportsmen

\section{COLLECTING TUB.}

\section{[Exhibit 3. Fig. 3, pl. crv.]}

This tub is convenient for use in connection with the trap described in exhibit 2. It is constructed of ordinary galvanized iron, is 3 feet in diameter, I4 inches deep, and has a 2 -inch flaring rim with outer circumference to fit the hoop of the cone-shaped trap. At each of two opposite points in the side is inserted a piece of perforated tin, 7 by ro inches, extending to within 4 inches of the bottom. Two handles are attached below the rim on the sides transverse to the perforated inserts, and the tub is painted inside and out.

When in use the tub is placed in a wood float 4 feet square, which permits it to be easily towed from nest to nest as the collections are made. In emptying the tub its contents are poured out over the solid side rather than the perforated.

This tub has the advantage of allowing the fish a free circulation of fresh water during the process of collecting, a condition very essential during warm weather. Necessity for changing the water is thus obviated, and handling of the fish, which should always be avoided as much as possible during warm weather, is minimized. 
FISH RETAINER.

[Exhibit 4. Fig. 4, pl. cv.]

This article is a convenient means of temporarily confining fish awaiting shipment. It is made of ordinary galvanized iron, and is in effect a taller and slenderer form of the collecting tub described in exhibit 3 , with the addition of a combined cover and bail. It is ro inches in diameter and 20 inches high, with a 2 -inch flaring rim and with two perforated strips of tin inserted opposite each other in the sides. The perforated inserts are 6 inches wide by $1+4$ inches in height, reaching from the lower edge of the rim to within 4 inches of the bottom of the receptacle. A stiff wire bail, to which the cover is fastened, is attached on the perforated sides, and the receptacle is painted.

When in use this retainer is set in a wooden float to prevent its sinking. Such floats may be constructed any length, to accommodate any number of retainers, but sections 26 inches wide and 7 feet long, which will accommodate Io retainers, are found to be most convenient. The apparatus is placed in fresh or running water, and the fish to be carried in one transportation can are placed in one retainer. In emptying the retainer its contents shoukl be poured out over the solid sides instead of the perforated, to prevent injury to the fish.

This device has the advantage of allowing shipments of fish to be prepared in advance of the time of departure, as a free circulation of water is permitted at all times and the fish can be held any reasonable number of days. It obviates extra handling of the fish, which is to be avoided as much as possible, and also enables one man to prepare the shipment without assistance, which is of great convenience for night departures.

\section{FISH ATTENDANT'S OUTFIT.}

\section{[Exhibit 5. Fig. 5, pl, cv.]}

This outfit comprises an aerating device and a combination ice pick and net, for use in the transportation of fish. The aerator consists of a cylindrical screen made of perforated zinc or tin, and a perforated funnel-shaped plunger with long handle. The screen is $6 \frac{1}{2}$ inches in diameter, 21 inches high, with a 2-inch slightly flaring collar at the top, has a perforated bottom, and is fitted with a wire bail. Two heavy wires, crossing each other at right angles, are soldered 2 inches from the bottom to prevent the plunger from striking the latter. The slender dimensions of the screen permit it to be inserted into the ordinary transportation can.

The plunger may be made of an ordinary tin funnel of 6 inches mouth diameter, a shallow tin pan of the same diameter, and a $1 / 4$-inch rod bent to form a loop at one end. The funnel is perforated with nail holes, as is also the bottom of the pan, and the latter, inverted, is soldered over the mouth of the 
funnel. The rod is inserted into the tube of the funnel, giving the plunger a total length of 18 inches.

To operate the aerator, the plunger is churned up and down in the screen. The screen filled with ice may be used also in cooling the water in which the fish are held.

Both as aerator and cooler this device is especially useful in transporting fry which are the more susceptible to injury in handling, such as shad, pike perch, and whitefish. With these means, moreover, the attendant can give proper attention to a large number of fish in a short space of time and with a minimum amount of labor.

The combined net and ice pick consists of a semicircular frame of 10 inches long dimension, made of no. 6 wire and covered with soft net of any desired mesh. This is fitted into a wooden handle, the opposite end of which holds a disappearing point 3 inches long, made of $1 / 4$-inch spring steel.

The net is of use in pouring water from transportation cans in order to replenish with a fresh supply, or for purposes of "doubling up" the contents of two cans, as may be necessary just before delivering from the train. It also takes the place of the siphon and scaff net usually carried by attendants in charge of shipments of fish, and since these and the ice pick are usually carried separately, the combination device reduces the number of articles from 3 to $\mathrm{I}$.

\section{SEINE FOR COLLECTING FINGERLING BASS.}

[Exxhibit 6. Fig. 6, pl. cvi.]

This seine, made of heavy bobbinet, is rigged upon two handles consisting of bamboo poles 14 feet in length. The web is 16 feet long and 4 feet wide, corked and leaded, and is attached at each end to a 4 -foot steel brail $1 / 4$ inch in diameter. The brails are fastened to the bamboo handles by strap-iron hinges, which allow the brails to break but one way. A heavy cord attached to the lower end of each brail passes through a screw eye in the handle at a point the brail's length distant from the hinge. In operation the seine is projected over the water with the brails extended, the back of the hinges downward. The handles are then given a half turn, allowing the brails to drop at the hinges, beyond the school of fish. The seine falls into the water and as soon as the leads touch the bottom of the pond the cords are tightened. Pulling from the lower end of the brails with the hinges bent, the cords draw upon the bottom of the seine, and it is easily hauled ashore.

The use of this seine, since it can be operated from shore, avoids the roiling of the water which occurs when the operators wade into the pond, and it makes possible the capture of fish at any desired time without drawing off the water. The seine is of advantage, among other purposes, in thinning out the fish from time to time to avoid exhaustion of the food supply and consequent cannibalism. 
[Lixhibit 7. Fig. 7, pl. cv1.]

This case is designed for shipping fish eggs either to foreign countries or points at any distance throughout the United States. It can be constructed of any sound lumber $7 / 8$ inch thick. The outer case is 2 feet wide, 2 feet high, and 3 feet long, with corners halved together to permit of nailing both sides and ends. Its sides are lined with asbestos packing paper, and the bottom with rubberoid roofing paper. The inner case is made of any light ${ }^{2} / 2$-inch lumber and is 9 inches high, 20 inches wide, and 32 inches long. The bottom is made of ordinary galvanized iron and has a slope of 2 inches toward the center to a waste pipe. The outside of this inner case is covered with rubberoid roofing paper.

Cleats in the ends in the bottom of the outer case support the inner one and make an air space below it, at the same time raising it so that it projects $1 / 2$ inches above the upper edge of the outer case. Between the walls of the onter and inner cases is a $\mathrm{I}$-inch air space, and this is closed at the top by means of a strip of lumber 2 inches wide inserted edgewise and flush with the inner wall, making the space airtight. This projection fits into the top of the case when the latter is closed.

The inside case is divided into five compartments, one at each end and in the middle for ice, the two others for trays, the partitions all flush with the inner case. The ice compartments are 3 inches wide and of the full width and depth of the inner case. The middle compartment is removable. The partitions are made of ${ }^{1}$ - -inch mesh galvanized-wire cloth and are held in place with I-incl cleats nailed upright to the sides of the inner case. These cleats also hold the tray stacks in vertical position, and the space they make allows for air circulation and the dripping of the ice hoppers which are to be placed above. It also allows easy access to the trays and permits of inspecting them at all times without disturbing the ice.

The case holds $2+$ trays for eggs, 12 in each compartment. The trays are made of ${ }^{1}{ }_{2}$-inch lumber and are $S^{{ }^{1}}{ }_{2}$ inches wide, $1 S^{1}{ }_{2}^{2}$ inches long, and $\mathrm{I}$ inch deep. The bottoms are of fine-mesh wire cloth. Each side of each tray is perforated with five equally spaced $1 / 2$-inch holes to allow air circulation.

Over each tray stack, resting upon the ends of the vertical cleats, is an ice hopper $10^{1} / 2$ inches wide, $18^{1} \frac{1}{2}$ inches long, and 2 inches deep, made of ordinary galvanized-iron bottom and sides, with wooden ends. The bottoms of the hoppers are perforated near the sides with ${ }^{1}{ }_{2}$-inch holes to allow the water to escape. Over the lower end of the waste pipe to prevent the cool air from escaping is a bowl-shaped cap which is always filled with water.

The top of the case, which is hinged, fits tightly over the rabbet formed by the projecting edge of the inner wall, making an air-tight chest. It is provided 
with two hasps in front, and is lined with a single sheet of asbestos, a layer of $1 / 2$-inch lumber, and over these a covering of rubberoid roofing.

The empty case weighs 88 pounds. The space devoted to ice will hold 60 pounds. Allowing 20 pounds for eggs and moss, the whole shipping weight would be 168 pounds. The case is designed to hold about 80,000 steelhead trout eggs, I 20,000 lake trout eggs, 250,000 brook trout eggs, or I,000,000 whitefish eggs.

This case has the advantage of allowing easy access to the eggs for inspection at any point en route. It permits of free circulation of air, thereby producing an even moisture and even temperature for all of the trays. For local shipments or field work the stacks of small trays, ice hoppers, and central ice compartment may be removed and large trays substituted, making a combination case, and avoiding the necessity for three separate styles, as usually required for different distances. The present case has also the advantage of carrying a maximum number of eggs at a minimum weight.

Coating the case inside with paraffin wax will prevent odors, or moisture from swelling the box.

The following tables record a 36-day test given a roughly constructed case of this type, beginning January 29 and ending March 5, I906. During the first 26 days the case contained 53,000 eyed lake trout eggs. It was not filled, only 10 of the 24 trays being used. Nine of them contained 5,000 eggs each and one had 8,000 .

RECORD OF FIRST 26 DAYS OF TEST.

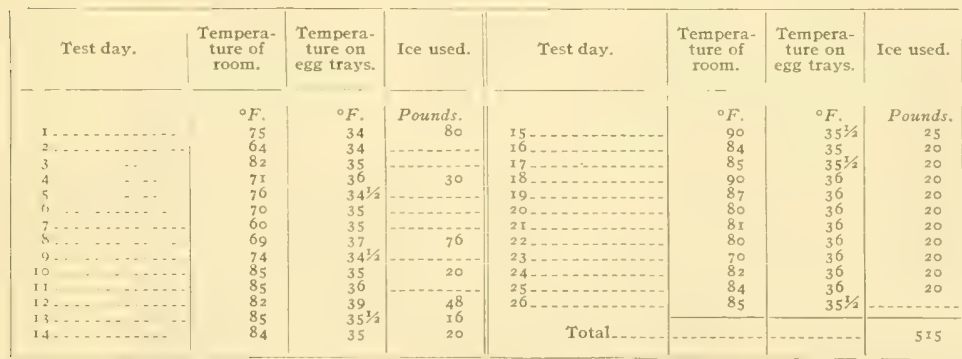

The eggs were looked over on the seventh day and 44 dead eggs were removed; on the sixteenth day I2I dead eggs were removed; on the twenty-sixth day I68.

On the sixteenth day the moss placed over the eggs was removed, the water squeezed out, and the moss then replaced.

The above test was made in the boiler room, and on the ninth day the case was moved nearer the boiler, which accounts for the rise in outside temperature. 
On the twenty-seventh day the eggs were all removed from the case, the latter thoroughly cleaned, and the tray containing 8,000 eggs was replaced for a further test of ten days. During the first five of these days the case was outside in a temperature ranging from $\mathrm{I}_{4}^{\circ}$ to $50^{\circ} \mathrm{F}$, the last five it was inside the hatching room at a temperature of $50^{\circ} \mathrm{F}$.

RECORD OF LAST IO DAYS OF TEST.

\begin{tabular}{|c|c|c|c|c|c|c|c|}
\hline \multirow{2}{*}{ Test day. } & \multicolumn{2}{|c|}{ Air temperature. } & \multirow{2}{*}{$\begin{array}{l}\text { Figg } \\
\text { tempera- } \\
\text { ture, } \\
\text { noon. }\end{array}$} & \multirow{2}{*}{ Test day. } & \multicolumn{2}{|c|}{ Air temperature. } & \multirow{2}{*}{$\begin{array}{l}\text { Egg } \\
\text { tempera- } \\
\text { ture, } \\
\text { noon. }\end{array}$} \\
\hline & Noon. & Midnight. & & & Noon. & Midnight. & \\
\hline & ${ }^{\circ} F$. & ${ }^{\circ} \mathrm{F}$. & ${ }^{\circ} \mathrm{F}$. & & ${ }^{\circ} F$. & ${ }^{\circ} \mathrm{F}$. & ${ }^{\circ} F$. \\
\hline $27 \ldots \ldots$ & 50 & 43 & 34 & $3^{2} \ldots \ldots$ & 50 & 50 & 33 \\
\hline $28 \ldots \ldots$ & 35 & $3 \tau$ & 34 & $33 \ldots \ldots$ & 50 & 50 & 34 \\
\hline $29 \ldots \ldots$ & 34 & 19 & 34 & $34 \ldots \ldots$ & 50 & 50 & 35 \\
\hline $30 \ldots \ldots$ & 23 & 14 & 33 & $35 \ldots \ldots$ & so & so & 35 \\
\hline $3 \mathrm{x} \ldots \ldots$ & 30 & 25 & 32 & $36 \ldots \ldots$ & 50 & 50 & 36 \\
\hline
\end{tabular}

These eggs were then removed to Clark hatching troughs and at the end of one week hatched, producing good strong healthy fry. The fry were held until the sac was nearly absorbed, and then planter.

The tray containing the 8,000 eggs stood the test for the entire thirty-six days, and at this rate would give the capacity of the case as 192,000 lake trout eggs, thus demonstrating that a much larger number of eggs than claimed for it can be safely transported in this case should occasion demand. During the above ro-day test but 20 pounds of ice was consumed. 


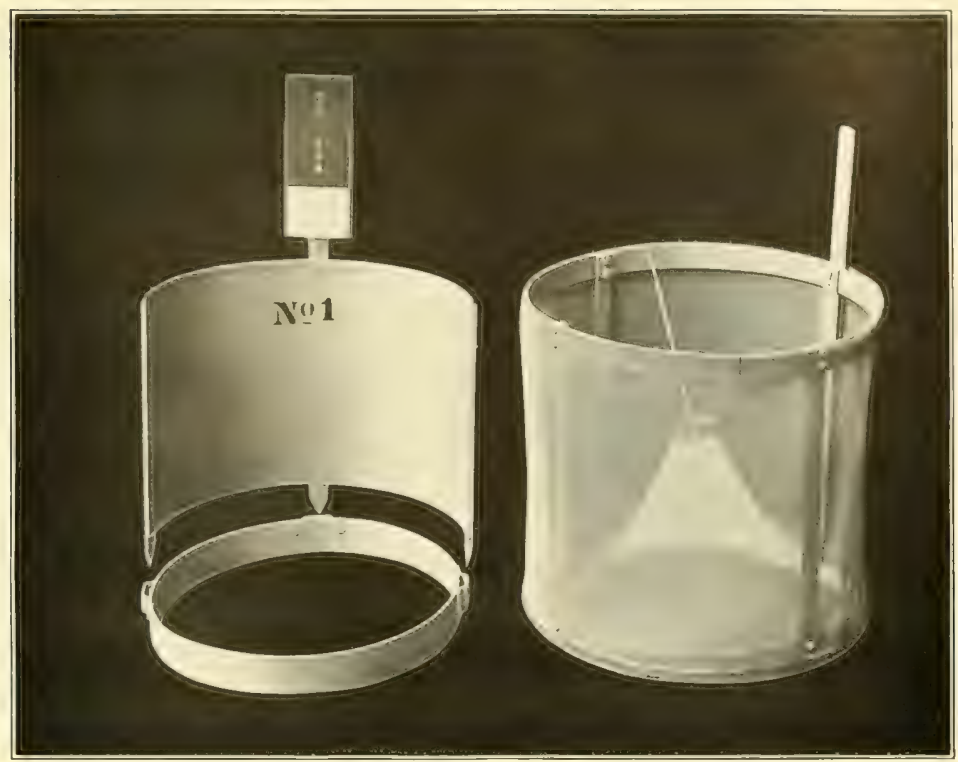

FiG, 1,-Artificial bass nest. Fig, 2,-Bass fry retaining screen and trap (Photographed from mode1s, which were sot built to scale.

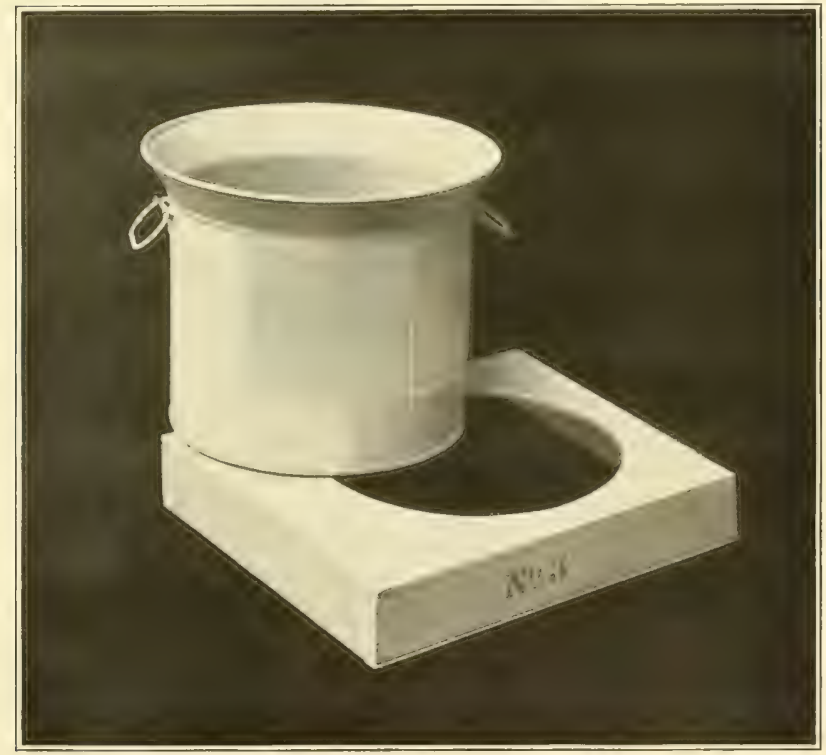

Fla. 3.-Collecting tub, with float. (Photographed from model.) 



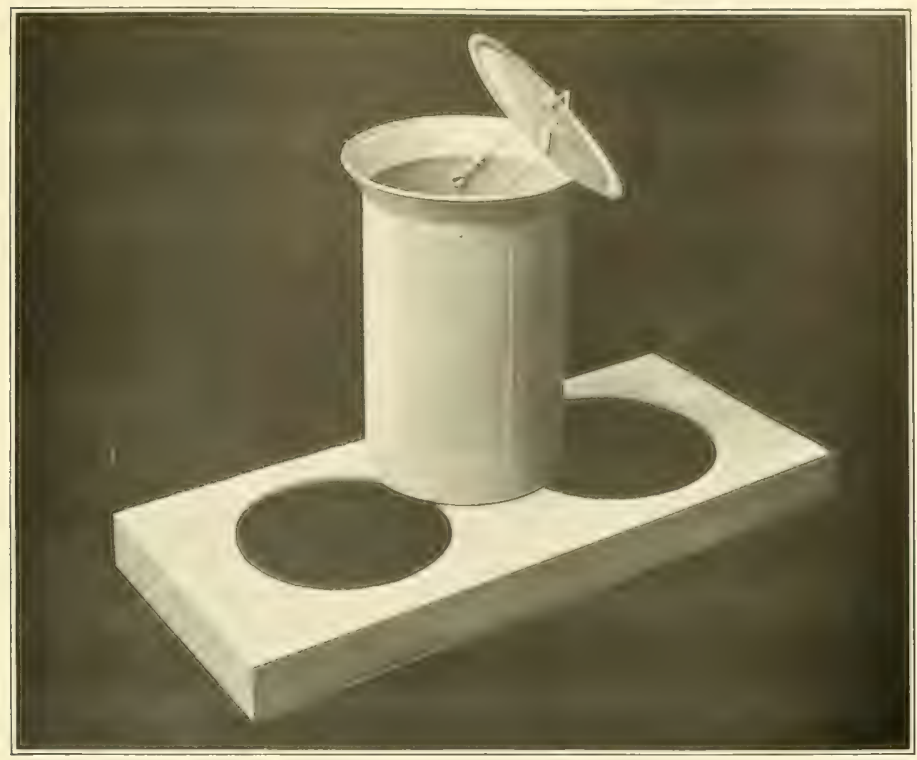

Fis: 4.-Fish retainer, with float. (I'hotographed from model.)

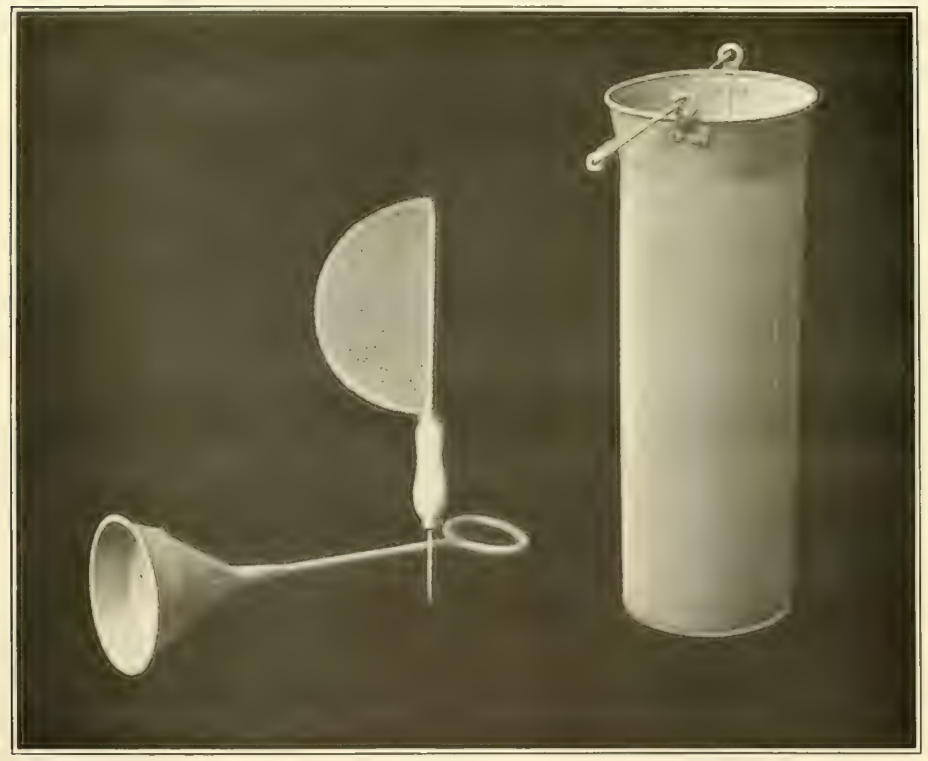

Ii Iw. 5-Fish attendant's outfit-aerator screen, plunger, combined ice pick and scaff net. (Photographed from model. 



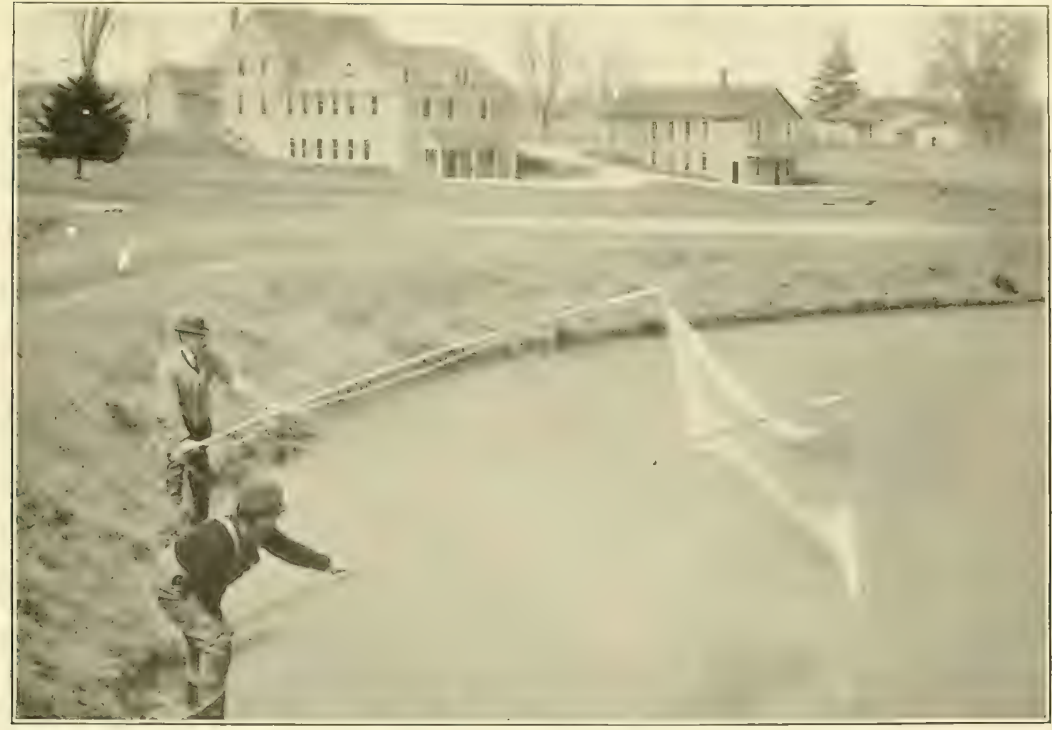

Fin. 6. - Seine for collecting fingerling hass,

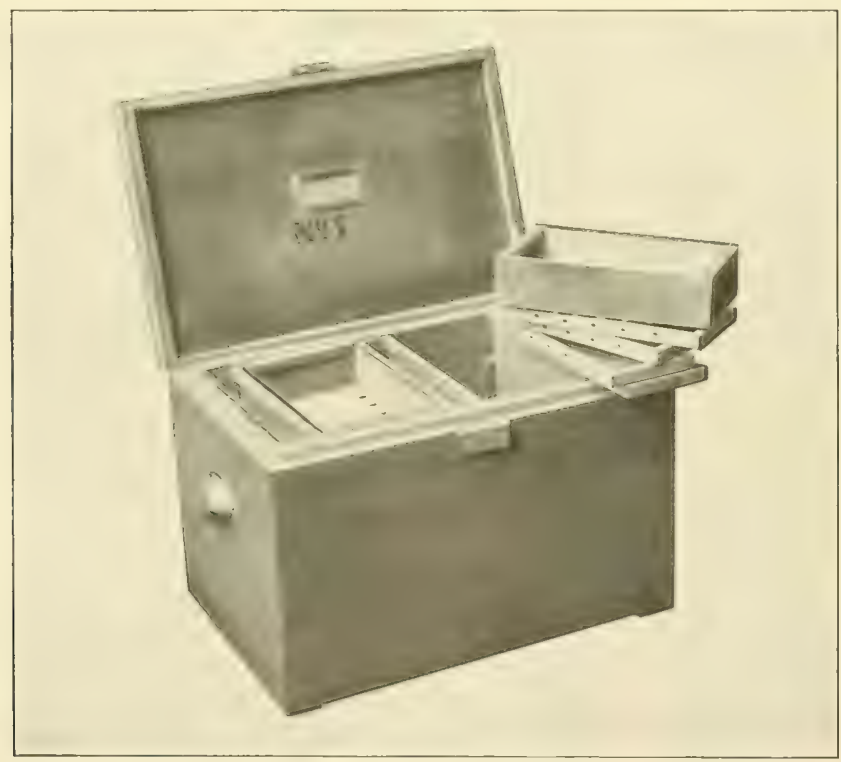

Frg. 7. - Shipping case for fish eggs. (Photographed from model, which was not built to scale.) 


